\title{
Design and CFD Simulation of Interior Wind Guides for the Four Dry Cooling Towers of Shazand Power Plant to Improve the Performance of Cooling System in Critical Peak Hours
}

\author{
Masoud Darbandi ${ }^{1}$, Kazem Mashayekh ${ }^{1}$, Pooya Javadpour-Langroodi ${ }^{1}$, Fakhereh Seyedi ${ }^{2}$, \\ Gerry E. Schneider ${ }^{3}$, Shahram Iranpak ${ }^{4}$, Javad Farhadi ${ }^{4}$ \\ ${ }^{1}$ Department of Aerospace Engineering, Sharif University of Technology, Tehran, Iran \\ darbandi@sharif.edu; kazem.mashayekh2016@student.sharif.edu; Javadpoor.pooya@ae.sharif.ir \\ ${ }^{2}$ Faculty of Mechanical and Energy Engineering, Shahid Beheshti University, A.C., Tehran, Iran \\ Fakhere.Seyyedi@gmail.com \\ ${ }^{3}$ Department of Mechanical and Mechatronics Engineering, University of Waterloo, Waterloo, ON, Canada \\ Gerry.Schneider@uwaterloo.ca \\ ${ }^{4}$ Shazand Thermal Power Plant, Shazand, Arak, Iran \\ Iranpak@shazandtpp.ir; J-farhadi@shazandtpp.ir
}

\begin{abstract}
Cooling systems are generally divided into two categories of dry and wet ones. The Heller cooling towers are considered as one main category of dry cooling systems. The performance of this type of tower is strongly influenced by the local atmospheric and climate conditions. In other words, since the cooling of condenser water is quite serious in these towers, in case of wind blow with the prevailing speed and direction, the cooling power of these towers is reduced and consequently, its effect appears directly in reduction of the power plant output power. One of the most effective solutions in the world, to reduce the negative effect of the wind on the performance of cooling towers, is to use suitable wind breaks inside and around the cooling towers. The purpose of this paper is to design wind breaks inside the cooling tower (interior wind guides) for four cooling towers in the Shazand thermal power plant and its analysis using the CFD simulation. To evaluate the thermal performance of wind breaks, the cooling towers are simulated with and without internal wind guides at wind speeds of 6,10 and $14 \mathrm{~m} / \mathrm{s}$ from the northwest and southwest directions.
\end{abstract}

Keywords: Dry cooling system, cooling towers, wind guides, numerical simulation, thermal performance

\section{Introduction}

The wind blowing around the cooling towers disrupts the natural draft and prevents the airflow from entering normally into the cooling system by creating low-pressure areas over it. Accordingly, the design of a suitable cooling system has very significant effects on the overall efficiency of the power plant cycle. In recent years, many researchers investigated the thermal performance of cooling towers in different environmental conditions, e.g., at different speeds, by numerical simulations and experimental works and developed empirical correlations to address the negative effect of wind blow.

Du Preez and Kröger [1-3] were among the first researchers to analyze the wind blow effect on cooling towers using experimental studies and numerical simulations. They investigated the effect of wind on the thermal performance of dry cooling towers of power plants. First, they collected data from the Heller dry cooling towers at the plant site using data collection techniques. The recorded data showed that the thermal performance of the tower is affected and would decrease with increasing the wind speed. Zhai and Fu [4] conducted both experimental and numerical studies for improving the efficiency of dry cooling towers using windbreak walls around the tower. They also extended their research to study two in-tandem towers. Their studies showed that windbreak walls, which were perpendicular to the direction of wind flow around the tower, would be an effective method to reduce the negative effect of wind and increase the thermal performance of towers. Guo et al. [5] used numerical approaches and assessed several different factors to enhance the cooling tower performance. For this purpose, they simulated two cooling towers in wind conditions of 12 and $20 \mathrm{~m} / \mathrm{s}$ speed. They practiced four different wind-break structures including cross-walls inside the tower, wind-break walls in front of the tower and perpendicular to the wind direction, cross line-screen inside the tower, and louvers in the cooling tower sectors. The 
results indicated a range of excellent to poor performance enhancement for implementation of wind-break walls, cross walls inside the tower, cross line-screen inside the tower and louvers, respectively. They also examined the optimum opening of louvers at studied wind speeds. Ma et al. [6] applied numerical simulations to investigate the optimum setting angle of the windbreak walls around the tower based on the wind speed. They simulated a cooling tower of 173 $\mathrm{m}$ height in wind conditions of 4, 8 and 12 meters per second. Their studies showed that the tangential component to the wind direction for air inlet to heat exchangers would depend on the wind speed and the use of windbreak walls perpendicular to the cooling tower circumference would not be optimal at low speeds. Darbandi et al. [7] applied numerical simulation by proposing new complementary thermo-aerodynamic equipment to investigate the performance of the Heller towers during wind conditions. In this study, the performance of the Heller cooling tower in different wind speeds of 4,8 and $12 \mathrm{~m} / \mathrm{s}$ were numerically simulated. The results indicated that by using complementary thermo-aerodynamic equipment, at least $55 \%$ of the cooling system performance can be compensated at different wind speeds.

The purpose of this study is to design interior wind guides to improve the thermal performance of the cooling towers at Shazand power plant site using computational fluid dynamics techniques. According to the studies conducted in Reference [8], the prevailing wind direction at the site of Shazand power plant is from the geographical northeast and southwest, with the wind speed of 6,10 and 14 meters per second. Therefore, these two directions and these wind speeds are used to investigate the thermal performance of the cooling towers of Shazand power plant with the suggestion of interior wind guides. Our literature survey shows that this research is carried out for the first time for the Shazand power plant in Arak.

\section{Numerical Simulation of Power Plant and the Cooling System}

This section provides details about the numerical simulation of this study. Hence, at the beginning of this section, the geometric modeling of the cooling towers of Shazand power plant site in the presence of the interior wind guides is conducted, and then, the generated grid is introduced. It is followed by describing the governing equations of the flow field, and at the end, the boundary conditions applied in this simulation as well as the solution algorithm are explained.

\subsection{Geometrical Model of the Cooling Towers}

The geometrical modeling of cooling towers of Shazand power plant in the presence of interior wind guides is comprehensively presented in this section. Figure 1 illustrates the computational domain with its dimensions and geographical directions. This domain is chosen large enough to have no effect on flow patterns near the cooling towers. The geographical directions shown in the figure are also very important and are the basis for wind directions, and analysis of the results as well. Figure (1b) shows the geometric model details of the four cooling towers of Shazand power plant with their respective dimensions and sizes.

For better identification of the guide design inside one of the cooling towers, Figure (2a) shows an isometric view of the interior wind guides inside one of the cooling towers with given sizes and dimensions. Figure (2b) shows top view of Heller cooling towers with interior wind guides and prevailing wind directions.

The arrangement of tower radiators is depicted in Figure (3a). It should be mentioned that the cooling towers radiators are Forgo type and their number in each cooling tower of Shazand power plant is 264 . The dimensions and sizes of the cooling tower radiators are shown in Figure (3b).

\subsection{Grid Generation}

After generating the geometric model, the grid mesh would be generated. At this stage, the modeling process continues with the creation of sufficient mesh elements. The calculation domain, cooling towers, and also their constituent cells are meshed to their finest element. The generated grid in the domain is of unstructured type. Of course, in radiators where heat transfer phenomenon occurs, a structured grid mesh is created.

A grid with approximately 13 million high quality cells is produced to generate mesh in the Shazand power plant cooling system with the proposed wind guides,. Figure (4a) shows the generated calculation grid of the overall domain and Figure 
(4b) displays the calculation grid on the interior wind guides in the Heller towers. To investigate the grid independent solution, the results of three large, medium and small size grids are achieved with an approximate amount of 9.5 million, 13 million, and 16 million elements, respectively. Due to close results of medium sized and small sized grid, the medium sized grid with about 13 million elements was used in the proceeding of numerical simulation and thermal performance investigation of cooling towers. It should be noted that the grid independence study of results will be presented in the relevant section.

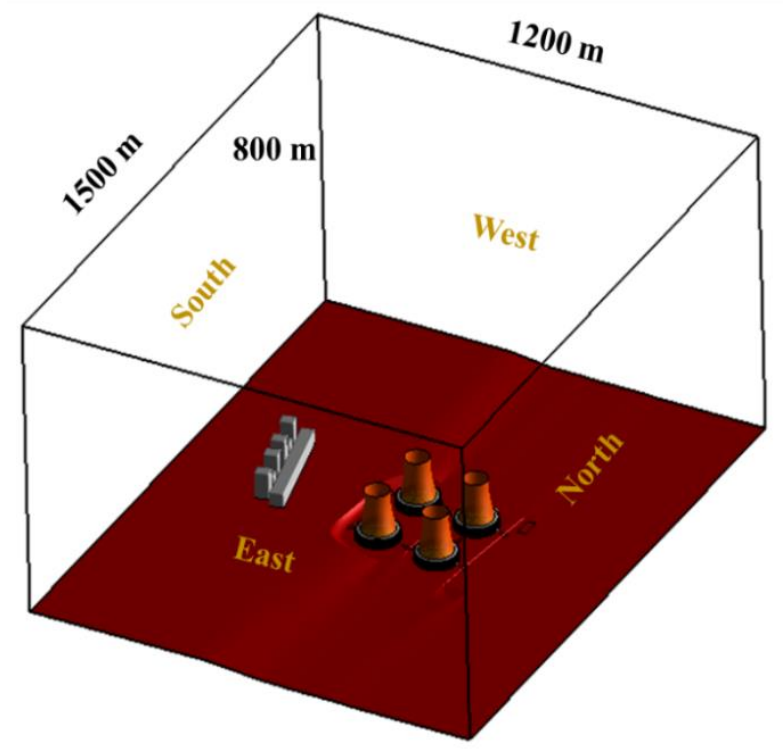

a

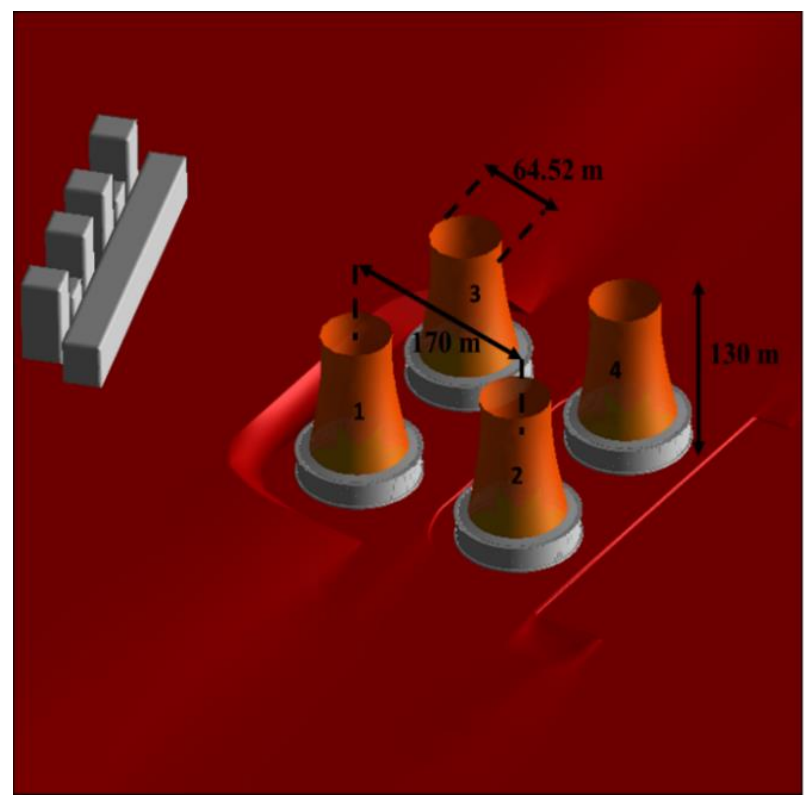

b

Figure 1: a) Dimensions and size of the computation domain b) Geometry modeling of power plant cooling towers with some dimensions and sizes

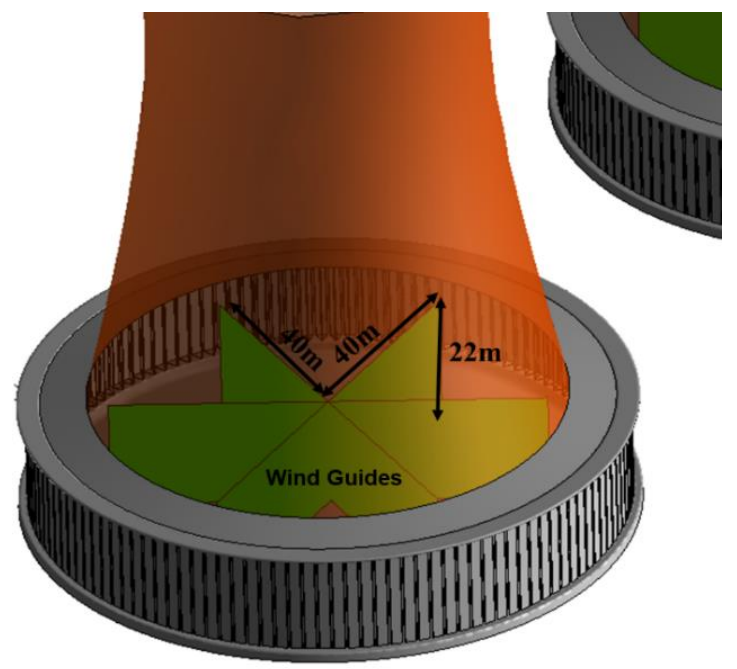

a
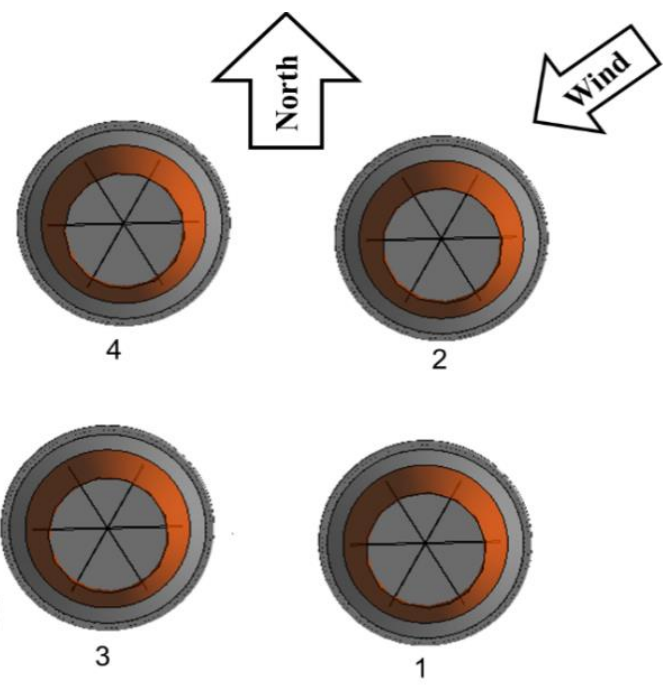

b

Figure 2: a) Isometric view of interior wind guides inside one of the cooling towers with size and dimensions b) top view of Heller cooling towers with interior wind guides and prevailing wind directions 


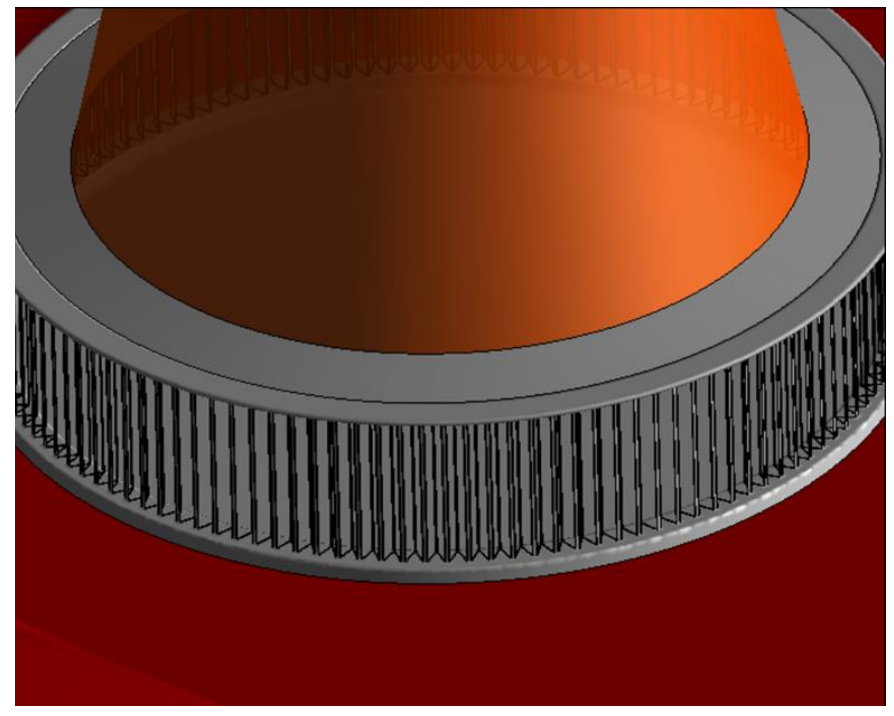

a

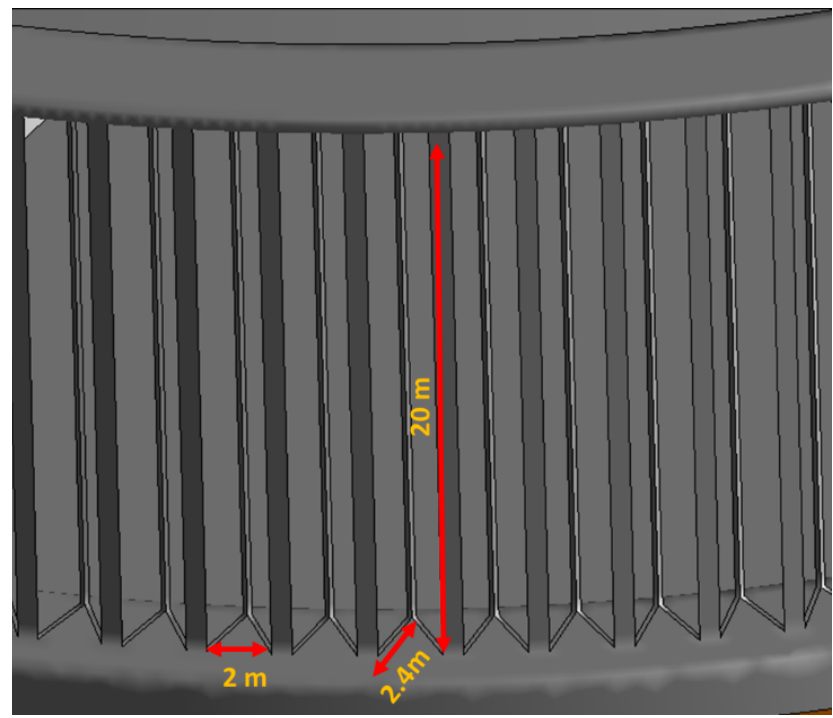

b

Figure 3: a) Isometric view of interior wind guides inside one of the cooling towers with sizes and dimensions b) top view of heller cooling towers with interior wind guides and prevailing wind directions in this study

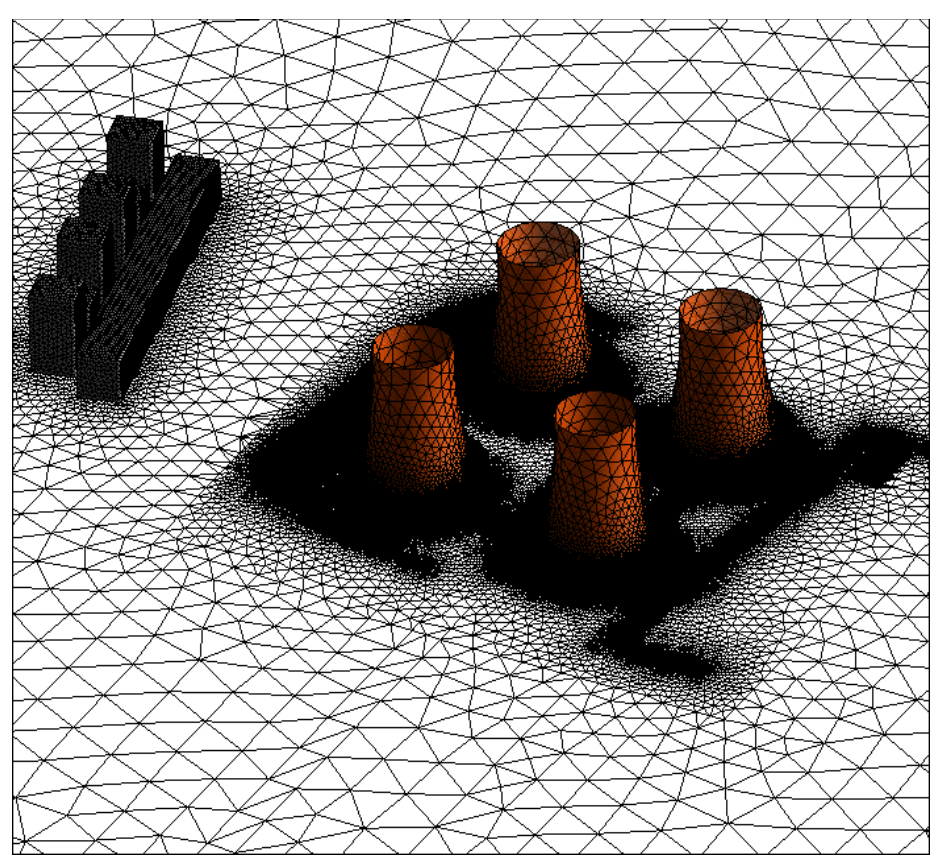

a

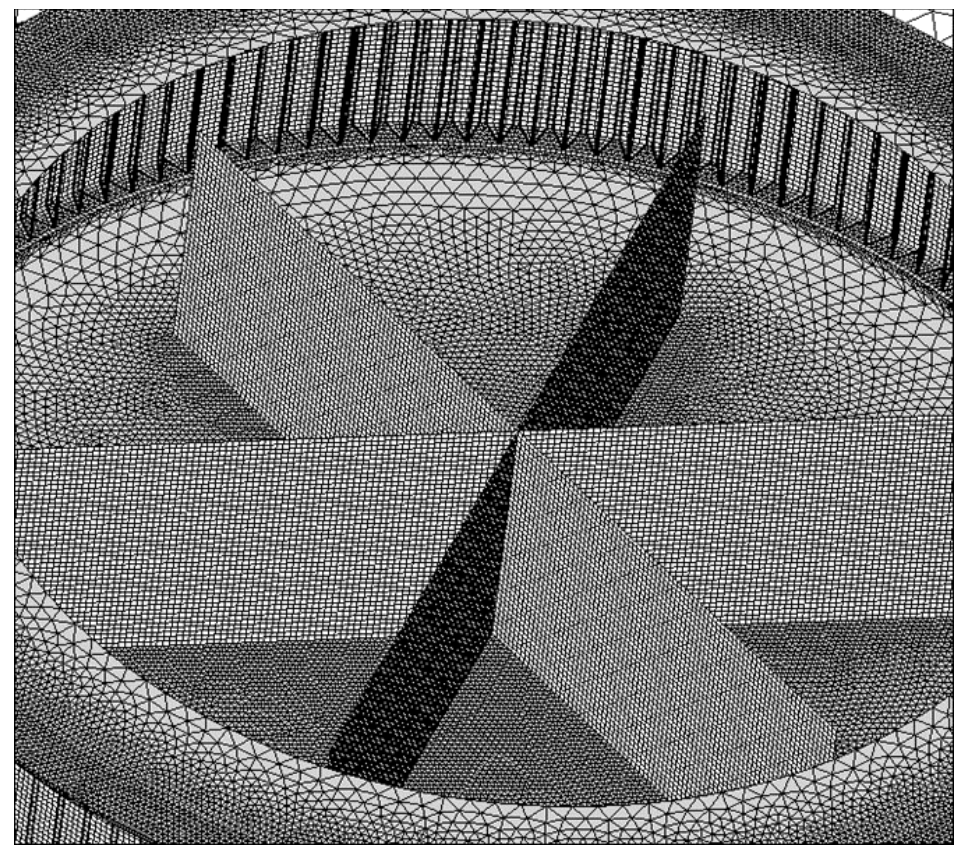

b

Figure 4: a) grid distribution in the overall domain of power plant b) Schematic of the generated grid rendered on the wind guides 


\subsection{Governing Equations of Flow Field}

The Navier-Stokes governing equations including mass, momentum and energy are solved for the steady-state incompressible viscous flow using the finite-volume method. The general transfer equation for an arbitrary parameter of $\phi$ is given by

$$
\nabla \cdot\left(\rho u \phi-\Gamma_{\phi} \nabla_{\phi}\right)=S_{\phi}
$$

In the above equation, $\rho$ and $\mathrm{u}$ are the fluid density and velocity and $\Gamma_{\phi}$ and $S_{\phi}$ the diffusion coefficient and the source term, respectively. Different values of them are presented in Table 1 . These equations will be integrated over all control volumes or the grid cells and then discretized.

Table 1: Definition of different parameters of governing equations [9]

\begin{tabular}{cccc}
\hline Equations & $\phi$ & $\Gamma_{\varphi}$ & $\mathrm{S}_{\varphi}$ \\
\hline Continuity & 1 & 0 & 0 \\
x-momentum & $\mathrm{u}_{1}$ & $\mu_{\mathrm{e}}$ & $-\frac{\partial p}{\partial x_{1}}+\frac{\partial}{\partial x_{1}}\left(\mu_{e} \frac{\partial u_{1}}{\partial x_{1}}\right)+\frac{\partial}{\partial x_{2}}\left(\mu_{e} \frac{\partial u_{2}}{\partial x_{1}}\right)+\frac{\partial}{\partial x_{3}}\left(\mu_{e} \frac{\partial u_{3}}{\partial x_{1}}\right)+\frac{\Delta p_{x_{1}} A_{c}}{V_{c}}$ \\
y-momentum & $\mathrm{u}_{2}$ & $\mu_{\mathrm{e}}$ & $-\frac{\partial p}{\partial x_{2}}+\frac{\partial}{\partial x_{1}}\left(\mu_{e} \frac{\partial u_{1}}{\partial x_{2}}\right)+\frac{\partial}{\partial x_{2}}\left(\mu_{e} \frac{\partial u_{2}}{\partial x_{2}}\right)+\frac{\partial}{\partial x_{3}}\left(\mu_{e} \frac{\partial u_{3}}{\partial x_{2}}\right)+\frac{\Delta p_{x_{2}} A_{c}}{V_{c}}$ \\
z-momentum & $\mathrm{u}_{3}$ & $\mu_{\mathrm{e}}$ & $-\frac{\partial p}{\partial x_{3}}+\frac{\partial}{\partial x_{1}}\left(\mu_{e} \frac{\partial u_{1}}{\partial x_{3}}\right)+\frac{\partial}{\partial x_{2}}\left(\mu_{e} \frac{\partial u_{2}}{\partial x_{3}}\right)+\frac{\partial}{\partial x_{3}}\left(\mu_{e} \frac{\partial u_{3}}{\partial x_{3}}\right)+\frac{\Delta p_{x_{3}} A_{c}}{V_{c}}$ \\
Energy & $\mathrm{T}$ & $\frac{\mu}{\operatorname{Pr}_{r}}+\frac{\mu_{t}}{\operatorname{Pr}_{t}}$ & $\frac{1}{c_{p}}\left(\frac{q A_{c}}{V_{c}}\right)$ \\
\hline
\end{tabular}

In the above table, $\mathrm{x}_{1}, \mathrm{x}_{2}, \mathrm{x}_{3}$ are the Cartesian co-ordinates, $\mathrm{u}_{1}$ velocity components in $\mathrm{x}$-direction $\left(\mathrm{m} \cdot \mathrm{s}^{-1}\right)$, $\mathrm{u}_{2}$ velocity components in y-direction $\left(\mathrm{m} . \mathrm{s}^{-1}\right), \mathrm{u}_{3}$ velocity components in z-direction $\left(\mathrm{m} . \mathrm{s}^{-1}\right), \mu_{\mathrm{e}}$ effective viscosity $\left(\mathrm{kg} \cdot \mathrm{m}^{-1} \cdot \mathrm{s}^{-1}\right), \mu_{t}$ turbulent eddy viscosity $\left(\mathrm{kg} \cdot \mathrm{m}^{-1} \cdot \mathrm{s}^{-1}\right)$, Pr the Prandtl number, $\mathrm{Pr}_{\mathrm{t}}$ the turbulent Prandtl number, $\mathrm{P}$ pressure $(\mathrm{pa}), \mathrm{A}$ area $\left(\mathrm{m}^{2}\right)$, $\Delta \mathrm{p}$ the pressure drop, $\mathrm{q}$ heat flux $\left(\mathrm{W} \cdot \mathrm{m}^{-2}\right)$, and $\mathrm{C}_{\mathrm{p}}$ the specific heat at constant pressure $\left(\mathrm{J} \cdot \mathrm{Kg}^{-1} \cdot \mathrm{K}^{-1}\right)$.

Conservation equations comprise of three equations, while equation unknowns include pressure, density, temperature, and velocity, which are a total of four unknowns all together. The fourth equation, which would help to solve the system of equations and unknowns, is called the state equation, which relates the density field to the pressure and temperature field as follows:

$$
\rho=\rho(P, T)
$$

By substituting suitable values of,$\Gamma_{\varphi}$ and $\mathrm{S}_{\varphi}$ parameters in the relevant equations, the $k-\varepsilon$ model can be obtained. Details of turbulence model equations are presented in Table 2. In this table, the $k$ and $\varepsilon$ parameters are the turbulent kinetic energy $\left(\mathrm{m}^{2} \cdot \mathrm{s}^{-2}\right)$ and turbulent kinetic energy dissipation rate $\left(\mathrm{m}^{2} \cdot \mathrm{s}^{-3}\right)$, respectively. 
Table 2: parameters of transfer equation for the turbulence model [9]

\begin{tabular}{lccc}
\hline Equations & $\varphi$ & $\Gamma_{\varphi}$ & $\mathrm{S}_{\varphi}$ \\
\hline Turbulent kinetic energy & $k$ & $\frac{\mu_{e}}{\sigma_{k}}$ & $\boldsymbol{G}_{K}+\boldsymbol{G}_{b}-\rho \varepsilon$ \\
$\begin{array}{l}\text { Rate of dissipation of } \\
\text { turbulent kinetic energy }\end{array}$ & $\varepsilon$ & $\frac{\mu_{e}}{\sigma_{\varepsilon}}$ & $C_{1 \varepsilon} \frac{\varepsilon}{k}\left(C_{k}+C_{3 \varepsilon} G_{b}\right)-C_{2 \varepsilon} \rho \frac{\varepsilon^{2}}{k}$ \\
\hline
\end{tabular}

The constants and other parameters appeared in this table are defined as [9]

$$
\begin{aligned}
& \mu_{e}=\mu+\mu_{t}, \mu_{t}=c_{\mu} \rho \frac{k^{2}}{\varepsilon}, c_{1 \varepsilon}=1.44, c_{2 \varepsilon}=1.92, c_{3 \varepsilon}=\tanh \left(\frac{U_{p a}}{U_{p e}}\right), G_{g}=-g \frac{U_{t}}{\rho \operatorname{Pr}} \frac{\partial P}{\partial y} ; C_{\mu}=0.09 \\
& ; \sigma_{k}=1 ; \sigma_{k \varepsilon}=1.3 ; \operatorname{Pr}=0.74 ; \operatorname{Pr}_{t}=0.85
\end{aligned}
$$

where $\mathrm{c}_{\mu}, \mathrm{c}_{1 \varepsilon}, \mathrm{c}_{2 \varepsilon}, \mathrm{c}_{3 \varepsilon}$ are four cconstants for the $k-\varepsilon$ turbulence model. Furthermore, $G_{g}$ is the production term and $\mathrm{g}$ is the gravity $\left(\mathrm{m} . \mathrm{s}^{-2}\right)$.

\subsection{Boundary Condition Implementations and Solution Algorithm}

In this section, suitable boundary conditions are introduced for the numerical simulation. The pressure outlet boundary condition is used when there is no wind in the considered direction. The boundary condition of velocity inlet is applied when there is wind blow in the simulation. Due to international standards, the wind flow gradient follows a specific profile that the wind speed value is zero at ground level and at 10 meter height. The characteristic curve of the radiators can be taken from the manufacturer's technical documents, laboratory. Figure $5 \mathrm{~b}$ shows the boundary condition for the radiators in the cooling tower on the model.

In order to correct the pressure and the coupling between pressure and velocity, the Simple algorithm was used to discretize equations. The turbulent steady-state flow and $\mathrm{k}-\varepsilon$ turbulence model are considered here. In discretizing the governing equations, the second-order upwind method for pressure, momentum and energy terms, and the first-order upwind method for the turbulence terms are applied. The convergence criteria of the solution are considered $10^{-4}$ for the continuity and momentum equations and $10^{-6}$ for the energy equation.

\section{Grid Independency of Results}

In this research, the parameter of heat released (MW) of one of the cooling towers in the design conditions $\left(31^{\circ} \mathrm{C}\right.$ temperature and no wind condition) is considered as a measure of grid independence of the results. Table 3 demonstrates the results for the three generated grids of large-sized with 9.5 million elements, medium-sized with 13 million elements and small-sized with 16 million elements. As can be seen, the results of the medium-sized grid of 13 million elements and the fine-sized grid of 16 million elements are very close to each other, so the medium grid with the number of 13 million grids is selected for the rest of the simulations.

Table 3: Results for the heat released by one of the Shazand power plant cooling towers considering different grid sizes

\begin{tabular}{cc}
\hline Grid numbers (million cells) & Heat release of one cooling tower \\
\hline 9.5 & 447 \\
13 & 454.5 \\
16 & 460.2 \\
\hline
\end{tabular}




\section{The validation activity}

In this section, the results for the simulation of thermal performance of one of the cooling towers of Shazand power plant without wind guides are presented and validated in the design conditions. The design point conditions of the Shazand power plant in this simulation are considered $31^{\circ} \mathrm{C}$ air temperature, $62^{\circ} \mathrm{C}$ temperature of inlet water to radiators and no wind.

In Table 4, the numerical simulation results are compared with the empirical values taken from the Shazand power plant at design point conditions. The small value of error between the present results and experimental data indicates the accuracy of the numerical simulation in the present study.

Table 4: Validation of numerical simulation results of cooling towers without wind guides

\begin{tabular}{cccc} 
Heat released of tower & Design value & Simulation value & Error percent(\%) \\
$(\mathrm{MW})$ & 457 & 455 & 0.4 \\
\hline
\end{tabular}

\section{The Results for the Cooling Towers with Wind Guides at Various Wind Conditions}

In this section, the simulation results of thermal performance of cooling towers are presented in the presence of wind guides at different wind conditions. The prevailing wind direction is from the northeast and southwest, and the wind speed is 6,10 and $14 \mathrm{~m} / \mathrm{s}$. The bar charts in Figures 5 to 7 compare the thermal performances of Heller towers with and without wind guides at three different wind speeds and two northeast and southwest directions. The horizontal axes show the Heller tower number and the vertical axes demonstrate the amount of heat released from each tower. The amount of heat released from each tower is also displayed on the bar charts. It should be noted that the blue color indicates the thermal performance of the cooling towers with wind guides and the green color indicates the thermal performance of cooling towers without wind guides.

Figure (5a) shows the thermal performance of the towers with and without wind guides at the wind speed of $6 \mathrm{~m} / \mathrm{s}$ from the northeast direction. According to the figure, the wind guides in Tower 4 comprise the most impact on the thermal performance while in other towers, according to the results, addition of wind guides has led to little impacts to even no effect on thermal performance. Figure $5 \mathrm{~b}$ shows the thermal performance of the towers with and without wind guides at a wind speed of $6 \mathrm{~m} / \mathrm{s}$ and from the southwesterly direction. Referring to shown bars, the wind guides in Tower 2 have the greatest impact and for the rest of the towers have almost no effect on their thermal performance. Figure (6a) illustrates the thermal performance of the towers with and without wind guides at a wind speed of $10 \mathrm{~m} / \mathrm{s}$ and from the northeast direction. Regarding this figure, the wind guides in Tower 1 lead to the highest effect on thermal performance in contrast to the other towers. According to the results, the effect of wind guides on the thermal performance of the towers is very small and insignificant. Figure $6 \mathrm{~b}$ depicts the thermal performance of the towers with and without wind guides at a wind speed of $10 \mathrm{~m} / \mathrm{s}$ and from the southwest direction. As can be seen, the wind guides result in the greatest impact on towers 3 and 4 and for towers 1 and 2 have no effect on their thermal performances. Figure (7a) shows the thermal performance of the towers in the presence and without consideration of wind guides at a wind speed of $14 \mathrm{~m} / \mathrm{s}$ and from the northeast direction. Regarding this figure, the wind guides have affected almost all the towers although the highest increase in thermal performance is attributed to towers 3 and 4. Figure (7b) shows the thermal performance of the towers with and without wind guides at a wind speed of $14 \mathrm{~m} / \mathrm{s}$ and from the southwest direction. As can be seen, the wind guides on Tower 4 had the greatest effect on its thermal performance and for other towers there are no significant influences. 


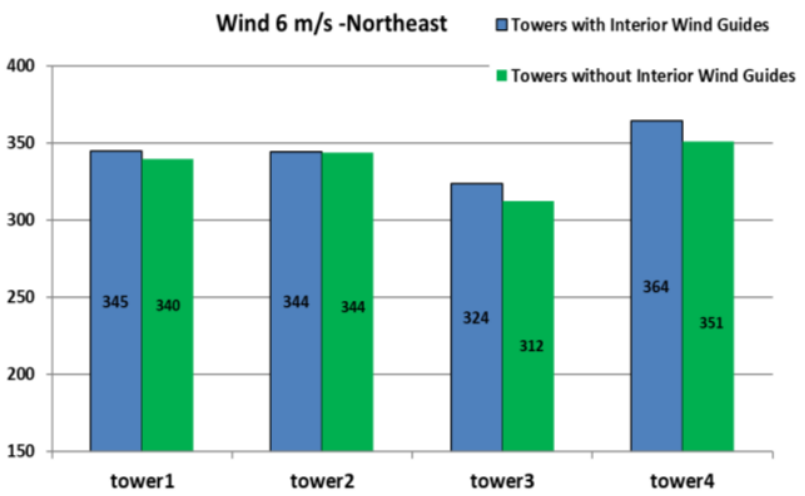

a

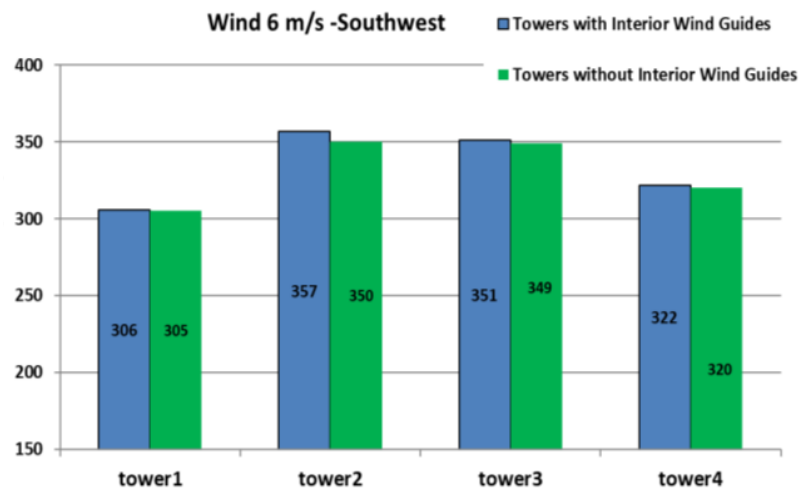

b

Figure 5: Thermal performance of cooling tower with and without wind guides at a wind speed of $6 \mathrm{~m} / \mathrm{s}$ from a) the northeast direction and b) the southwest directions

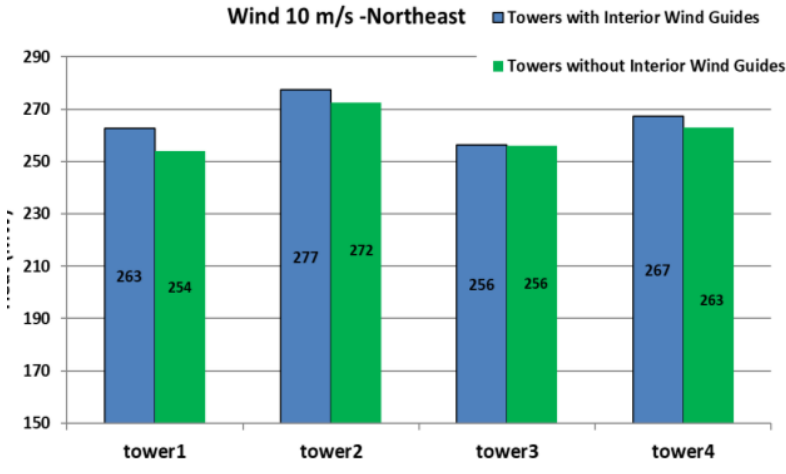

a

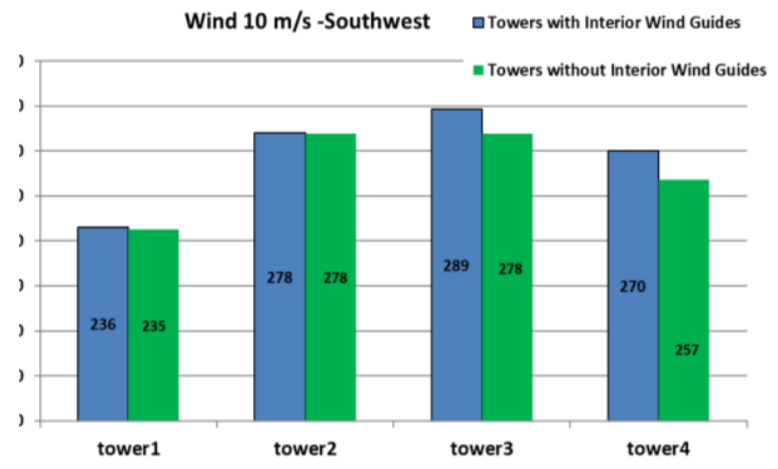

b

Figure 6: Thermal performance of cooling tower with and without wind guides at a wind speed of $10 \mathrm{~m} / \mathrm{s}$ from a) the northeast direction and $b$ ) the southwest directions

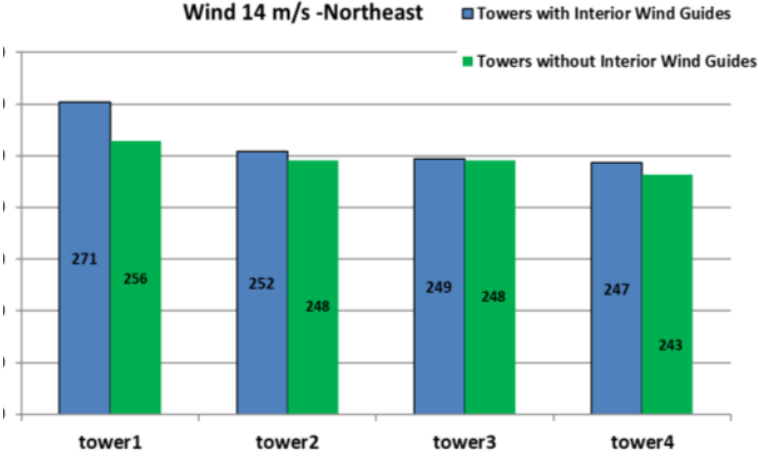

a

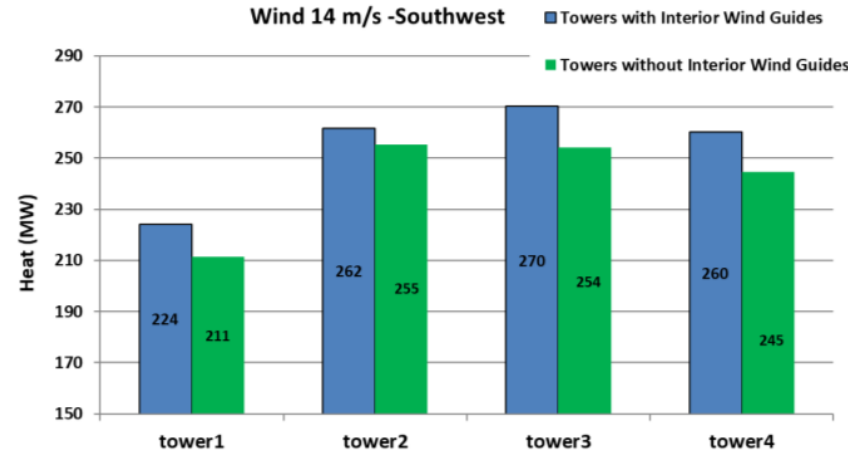

b

Figure 7: Thermal performance of cooling tower with and without wind guides at a wind speed of $14 \mathrm{~m} / \mathrm{s}$ from a) the northeast direction and b) the southwest directions 


\section{Conclusion}

The aim of this paper was to design suitable interior wind guides to improve the thermal performance of four cooling towers of the Shazand Power Plant using the numerical simulation tools. In this regard, the thermal performance of Shazand power plant cooling towers were studied with and without the designed interior wind guides at wind speeds of 6 , 10 and 14 meters per second, from the northeast and southwest geographical directions. The results of simulations showed that addition of wind guides in general, had a minor effect on the major thermal performance of the cooling towers of the Shazand power plant. The highest increase in the thermal performance of cooling towers was attributed to the wind speed conditions of $14 \mathrm{~m} / \mathrm{s}$ from the northeast and southwest directions. According to the obtained results, it can be emphasized that there is no economic justification to design, construct, install, and use the interior wind guides in the Shazand power plant. There is no opportunity to improve the present performance significantly using the interior wind guides.

\section{Acknowledgement}

The authors would like to acknowledge the financial grant received from the Shazand Thermal Power Plant. It is highly appreciated. The authors also would like to appreciate the help received from the Department of Research and Technology of Sharif University of Technology.

\section{References}

[1] Du Preez, A. F., and D. G. Kröger. "The effect of the heat exchanger arrangement and wind-break walls on the performance of natural draft dry-cooling towers subjected to cross-winds." Journal of wind engineering and industrial aerodynamics 58, no. 3 (1995): 293-303.

[2] Du Preez, A. F., and D. G. Kröger. "Effect of the shape of the tower supports and walls on the performance of a drycooling tower subjected to cross winds." Heat transfer engineering 16, no. 2 (1995): 42-49.

[3] Du Preez, A. F., and D. G. Kröger. "Effect of wind on performance of a dry-cooling tower." Heat Recovery Systems and CHP 13, no. 2 (1993): 139-146.

[4] Zhai, Z., and S. Fu. "Improving cooling efficiency of dry-cooling towers under cross-wind conditions by using windbreak methods." Applied Thermal Engineering 26, no. 10 (2006): 1008-1017.

[5] Gu, Hongfang, Haijun Wang, Yuqian Gu, and Jianan Yao. "A numerical study on the mechanism and optimization of wind-break structures for indirect air-cooling towers." Energy Conversion and Management 108 (2016): 43-49.

[6] Ma, Huan, Fengqi Si, Yu Kong, Kangping Zhu, and Wensheng Yan. "Wind-break walls with optimized setting angles for natural draft dry cooling tower with vertical radiators." Applied Thermal Engineering 112 (2017): 326-339.

[7] Darbandi, M., Javadpoor, P., Khademi, A., and Behrouzifar, A. "Improving Thermal Energy Transfer Performance of Natural Draft Cooling Towers Using Thermo-Aerodynamic Components." ASHRAE Topical Conference Proceedings. American Society of Heating, Refrigeration and Air Conditioning Engineers, Inc., 2019.

[8] The Center for Developing Modern Energy Systems, Sharif High Tech Park, Sharif university of Technology, "Technical and economic feasibility studies on hybrid implementations of wind guides and TOSAN auxiliary cooling system to improve the thermal performance of Heller towers in Shazand power plant," Report Phase 1, 2021.

[9] Khamooshi, Mehrdad. The effect of wind on multiple, short, natural-draft dry cooling towers. Diss. Auckland University of Technology, 2020. 